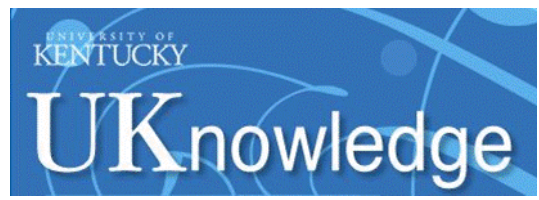

University of Kentucky

UKnowledge

$7-2020$

\title{
Dynamic Modeling and Optimal Design for Net Zero Energy Houses Including Hybrid Electric and Thermal Energy Storage
}

\author{
Huangjie Gong \\ University of Kentucky, huangjie.gong@uky.edu \\ Vandana Rallabandi \\ University of Kentucky, vandana.rallabandi@uky.edu \\ Dan M. Ionel \\ University of Kentucky, dan.ionel@uky.edu \\ Donald G. Colliver \\ University of Kentucky, dcolliver@uky.edu \\ Shaun Duerr \\ Marquette University
}

See next page for additional authors

Follow this and additional works at: https://uknowledge.uky.edu/peik_facpub

Part of the Power and Energy Commons

Right click to open a feedback form in a new tab to let us know how this document benefits you.

\section{Repository Citation}

Gong, Huangjie; Rallabandi, Vandana; Ionel, Dan M.; Colliver, Donald G.; Duerr, Shaun; and Ababei, Cristinel, "Dynamic Modeling and Optimal Design for Net Zero Energy Houses Including Hybrid Electric and Thermal Energy Storage" (2020). Power and Energy Institute of Kentucky Faculty Publications. 4. https://uknowledge.uky.edu/peik_facpub/4

This Article is brought to you for free and open access by the Power and Energy Institute of Kentucky at UKnowledge. It has been accepted for inclusion in Power and Energy Institute of Kentucky Faculty Publications by an authorized administrator of UKnowledge. For more information, please contact UKnowledge@lsv.uky.edu. 


\title{
Dynamic Modeling and Optimal Design for Net Zero Energy Houses Including Hybrid Electric and Thermal Energy Storage
}

\author{
Digital Object Identifier (DOI) \\ https://doi.org/10.1109/TIA.2020.2986325
}

\section{Notes/Citation Information}

Published in IEEE Transactions on Industry Applications, v. 56, issue 4.

(C) 2020 IEEE Copyright Notice. "Personal use of this material is permitted. Permission from IEEE must be obtained for all other uses, in any current or future media, including reprinting/republishing this material for advertising or promotional purposes, creating new collective works, for resale or redistribution to servers or lists, or reuse of any copyrighted component of this work in other works."

The document available for download is the authors' manuscript version that is accepted for publication. The final published version is copyrighted by IEEE and will be available as: H. Gong, V. Rallabandi, D. M. Ionel, D, Colliver,S. Duerr, and C. Ababei, "Dynamic Modeling and Optimal Design for Net Zero Energy Houses Including Hybrid Electric and Thermal Energy Storage," in IEEE Transactions on Industry Applications.

\section{Authors}

Huangjie Gong, Vandana Rallabandi, Dan M. Ionel, Donald G. Colliver, Shaun Duerr, and Cristinel Ababei 


\title{
Dynamic Modeling and Optimal Design for Net Zero Energy Houses Including Hybrid Electric and Thermal Energy Storage
}

\author{
Huangjie Gong, Student Member, IEEE, Vandana Rallabandi, Senior Member, IEEE, Dan M. Ionel, Fellow, IEEE, \\ Donald Colliver, Shaun Duerr, Member, IEEE, Cristinel Ababei, Senior Member, IEEE
}

\begin{abstract}
Net zero energy (NZE) houses purchase zero net metered electricity from the grid over a year. Technical challenges brought forth by NZE homes are related to the intermittent nature of solar generation, and are due to the fact that peak solar generation and load are not coincident. This leads to a large rate of change of load, and in case of high PV penetration communities, often requires the installation of gas power plants to service this variability. This paper proposes a hybrid energy storage system including batteries and a variable power electric water heater which enables the NZE homes to behave like dispatchable generators or loads, thereby reducing the rate of change of the net power flow from the house. A co-simulation framework, INSPIRE+D, which enables the dynamic simulation of electricity usage in a community of NZE homes, and their connection to the grid is enabled. The calculated instantaneous electricity usage is validated through experimental data from a field demonstrator in southern Kentucky. It is demonstrated that when the operation of the proposed hybrid energy storage system is coordinated with solar PV generation, the required size and ratings of the battery would be substantially reduced while still maintaining the same functionality. Methodologies for sizing the battery and solar panels are developed.
\end{abstract}

Index Terms-Net Zero Energy (NZE) houses, Home Energy Management (HEM), Electrical Water Heater (EWH), Battery Energy Storage System (BESS), Virtual Power Plant (VPP).

\section{INTRODUCTION}

According to the U.S. Department of Energy, a net zero energy (NZE) home is a residence with zero net energy usage, meaning the total amount of energy used by the house on an annual basis is less than or equal to the amount of renewable energy generated on site [1]. Due to the increasing energy usage and concerns over greenhouse gas emissions, efforts have been made to implement more NZE homes both in and outside of the USA. For instance, as per the California Public Utilities Commission, all new residential constructions will be NZE by the year 2020 [2]. The 'Nearly zero-energy buildings' proposed by European Commission requires all EU Member States to have all new buildings to be nearly zero-energy by the end of 2020 [3]. As a result, a growing number of US states and countries have started to build NZE residences at different scales, varying from single homes to big neighborhoods, and their objectives range from reduced energy usage to net positive energy input to the grid.

The NZE homes typically incorporate solar photovoltaic (PV) systems as the main source of energy [4], [5]. Solar PV generation is largely decided by external environment conditions, leading to unpredictability and stochastic properties. The mismatch between the peaks of PV generation and residential load leads to variations in the net power flow, which causes the "duck curve" phenomenon [6]. In addition, the power flow due to surplus solar generation can potentially exceed the rated capacity of distribution lines and transformers. Curtailment of solar energy and the use of energy storage systems are common methods to overcome these challenges [7].

Such challenges are further exacerbated when a number of PV systems are congregated in the same neighborhood comprising NZE homes [8]. Solar generation curtailment, and energy storage are potential solutions to these challenges. Solar generation can be curtailed by operating the PV system at limited power rather than at the maximum power point. However, PV curtailment leads to inefficient renewable energy harvesting, and a higher installation capacity is required to achieve the NZE target.

Furthermore, systematic guidelines for the sizing of solar PV and energy storage systems to achieve NZE operation have not yet been developed and reported. Difficulties in a uniform approach arise because the energy usage in houses differs due to weather, location, human behavior and other factors. Furthermore, the PV curtailment policies in different areas also have important influences on the required PV capacity [9].

Battery energy storage systems (BESS) provides increased flexibility to the NZE residences. The proposed power electronic interface in this paper interconnects the BESS, PV, the grid and other house loads. The stability and control for a PV-BESS system were studied in recent research works [10], [11]. The stability of power converters, which are the main components of such a power electronic interface, were studied [12], [13].

The sizing for BESS is mainly determined by factors including building characteristics, utility tariffs and the BES operating schedule [14]-[16]. A placement planning scheme for the optimal combination of PV and BES with stochastic optimization is proposed [17]. A design day is typically used to describe maximum conditions for the HVAC system and the building characteristics [18]. The BES sizing could be realized based on the representative design days. 
Apart from the BESS, an electric water heater (EWH) can be regarded as a uni-directional energy storage system. Research works regarding EWH as a deferrable load realize the home energy management (HEM) by changing its working status between "on" and "off" [19]-[21]. Others works have demonstrated the use of EWH in conjunction with batteries. For instance, an EWH coupled with the DC bus is used to suppress the power fluctuation in systems with large batteries [22]. This paper proposes the control of batteries, together with water heaters to operate a community of grid connected NZE homes as dispatchable generators, which can provide constant grid power flow for specified durations of time on typical winter and summer days.

The development of such control algorithms for home based energy storage systems requires accurate load modeling. Most research works report simulation of the residential electricity consumption by either mathematical models or building energy simulation software. The mathematical house energy usage models sum the typical household loads [23]-[32]. Coupling factors including solar illumination, radiant energy from appliances and people, impact of airflow, and etc. add complexities to the mathematical models. There is a trade-off between the accuracy and complexity of such models.

Other research works use building energy simulation software to produce the static house load profiles. The software tools such as EnergyPlus, Building Energy Optimization (BEopt), eQUEST, etc., are able to model houses with various characteristics in different locations [33]-[40]. The Integrated District Energy Assessment (IDEA) provides another method to model and control the building energy usage considering the environment, networks and building characteristics [41].

This paper proposes a co-simulation framework named INSPIRE+D, incorporating freeware including Python, BEopt, EnergyPlus and OpenDSS. The proposed co-simulation framework is capable of simulating the energy usage and instantaneous solar generation for a large community of NZE homes, and their interconnection with the grid. An important feature of INSPIRE+D is that it utilizes OpenDSS, widely used by the utilities, in contrast with more academic approaches based on MATPOWER. There are only very few such simulation tools available, including the authors' previous Smartbuilds, the PNNL developed GridLAB-Dm and the extremely recently announced HELICS by PNNL, which is yet to be used by the professional community. [42] The software framework provides a virtual building, and offers a platform for the testing of various energy storage operating schedules to meet the specified objectives.

A hybrid energy storage system incorporating a battery and a variable power electric water heater $(\mathrm{EWH})$ was proposed in a previous conference paper by the same group of authors [43]. It is demonstrated that the required battery capacity is reduced by utilizing the EWH along with the battery to form a hybrid PV energy storage system (HyPVESS). The control objective in this study is to realize dispatchable output for the NZE community while harvesting the maximum of PV generation.
This paper features new contributions including the introduction of the INSPIRE+D co-simulation framework, as well as validation of the calculated energy usage. The electricity consumption is calculated for California and Kentucky, and validated using data from the California Building Energy Code Compliance (CBECC) and experimental data from the existing low-cost low-income near-NZE houses in southern Kentucky, respectively. Furthermore, a method for sizing for the capacity of the solar PV and energy storage systems to meet the NZE mandate and minimize the side impact of the renewables is proposed.

Main contributions of this paper include 1) a co-simulation framework capable of energy use and on site renewable energy generation modeling with simulations validated on field demonstrators of low-cost low-income NZE homes; 2) a new hybrid energy storage technology with battery and electric water heater to reduce required battery energy capacity; 3) the scheduling of home energy storage systems so that the homes operate as dispatchable generators; 4) systematic sizing and formulation for the hybrid energy storage system; 5) the aggregated behavior of the NZE homes when interconnected with the grid.

The paper is organized as follows: The co-simulation framework is introduced in section II, and the sizing of the solar PV system and validation of energy usage calculations for the NZE homes are presented in section III. Section IV deals with the sizing and control for the HyPVESS, case studies are discussed in section $\mathrm{V}$, and conclusions are drawn in section VI.

\section{House Energy Modeling in the Software FRAMEWORK}

The proposed co-simulation software framework comprises freeware including BEopt, EnergyPlus, OpenDSS, BCVTB, and Python (Fig. 1). The name for the co-simulation framework is "Integrated Network simulation for Smart Powerflow In Residences using EnergyPlus and OpenDSS" (INSPIRE+D, pronounced as INSPIRED). INSPIRE+D provides an improved platform for instantaneous building energy usage modeling and simulation, based on the freeware BEopt, EnergyPlus from Lawrence Livermore National Lab, and simulation of distribution power networks, using the frequency domain OpenDSS freeware from EPRI. INSPIRE+D is a Python-based co-simulation tool which allows residential load calculation, district network analysis and control realization in just one model. INSPIRE+D is capable of simulating 1000s of homes in parallel at one minute intervals. Each thread handles one EnergyPlus process and needs approximately 1GB of RAM. The time required for the whole simulation depends on the time-step and running period. A typical simulation for the entire year with a time-step of 5-minutes takes approximately 10 minutes to complete.

Solar generators, battery energy storage, control for water heater and heating ventilation and air-conditioning (HVAC) systems can also be included in the framework. The software 


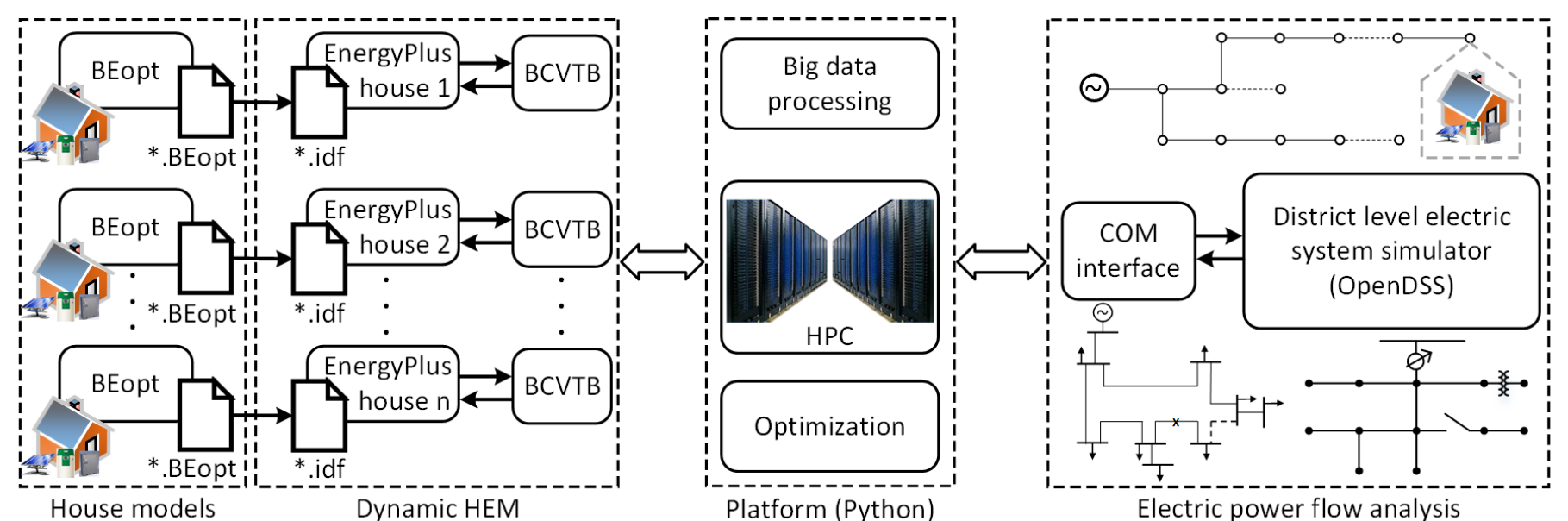

Figure 1. The INSPIRE+D co-simulation framework, including four parts. Thousands of single house energy models can be simulated in parallel through a high performance computing (HPC) system.

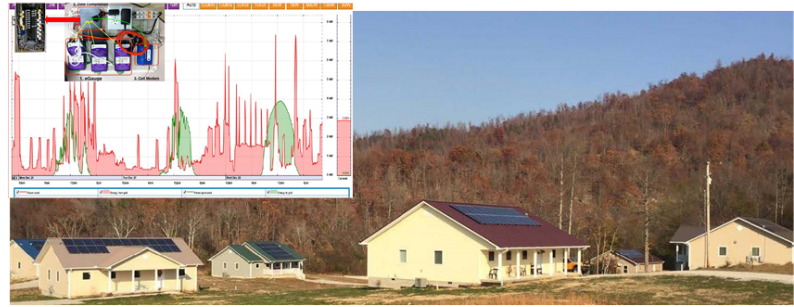

Figure 2. A newly developed field demonstrator with twelve near-NZE houses in southern Kentucky, which are modeled within the INSPIRE+D cosimulation framework and validated with measured load data.

framework uses BEopt and EnergyPlus for building simulations, which allow both fast house energy modeling as well as dynamic instantaneous load simulation.

BEopt converts the geometric data and the schedules of the appliances for the user-defined house to input data file (IDF), which serves as the input for the EnergyPlus software. The IDF is an ASCII file containing the data describing the building to be simulated. EnergyPlus is capable of simulating domestic energy usage to a time step of 1-minute. The Building Controls Virtual Test Bed (BCVTB) is a software environment that allows coupling different simulation programs [44], [45].

The proposed co-simulation framework is capable of running thousands of EnergyPlus processes in parallel in the platform powered by the high performance computing (HPC) system. The net power flow from all the houses form the loads of the electric power system, which is simulated by the OpenDSS software. Energy storage control algorithms to achieve different objectives can be implemented in the proposed INSPIRE+D framework, both at the single house and distribution power system levels. The calculated energy usage is validated using examples based on California Building Energy Code Compliance (CBECC) and the near-NZE subdivision in southern Kentucky (Fig. 2).

\section{VAlidation FOR House ENERgy Models}

The INSPIRE+D co-simulation framework provides instantaneous home energy usage data, based on the floorspace, occupancy, and ambient conditions, which enables testing of the developed real-time control for advanced home appliances. The building simulations are validated by comparing with experimental data from field demonstrator homes in Southern Kentucky. The calibration for the developed house energy usage models is carried out for three types of loads, respectively. The three types of loads are: the HVAC system, which reflects the influences of the external temperature; the EWH, as it is of interest for the proposed hybrid energy storage system; and the remaining loads.

The HVAC load depends on the nominal rating, thermostat set-points, ambient temperature as well as building insulation and materials. The EWH load is decided by the nominal power rating, the set point, the deadband, and the hot water draw of different equipment including clothes washer, dish washer, shower, bath, etc.

Two weeks, one in summer and the other in winter are chosen for the validation such that the house electricity consumption and PV generation under different external environments are fully represented.

The reference energy usage and PV generation for a single house are from two different sites, California and southern Kentucky. The home energy model for California is validated based on the weekly energy usage complying with the California Building Energy Code Compliance Residential Standards (CBECC-Res). The reference data is simulated from the CBECC-Res 2019 software. The EnergyPlus (EP) house model is validated as it has good agreement with the CBECCRes in both weekly and annually basis (Table. I).

The home energy model representing house in southern Kentucky has good agreement with the experimental data in weekly basis (Table. II). Due to the mild climate in Kentucky, HVAC consumption throughout the whole year is fairly low. It is worth noticing the electricity consumed by the EWH 
Table I

WEEKLY AND ANNUAL ENERGY USAGE FOR AN EXAMPLE CALIFORNIA HOUSE (KWH).

\begin{tabular}{lcccccc}
\hline \multirow{2}{*}{ Load type } & \multicolumn{2}{c}{ Winter } & \multicolumn{2}{c}{ Summer } & \multicolumn{2}{c}{ Annual } \\
\cline { 2 - 7 } & CBECC & EP & CBECC & EP & CBECC & EP \\
\hline HVAC & 11 & 12 & 294 & 292 & 5,625 & 5,628 \\
EWH & 59 & 59 & 23 & 23 & 1,664 & 1,679 \\
Other loads & 101 & 106 & 88 & 82 & 4,741 & 4,816 \\
Total usage & 170 & 177 & 404 & 398 & 12,030 & 12,122 \\
\hline
\end{tabular}

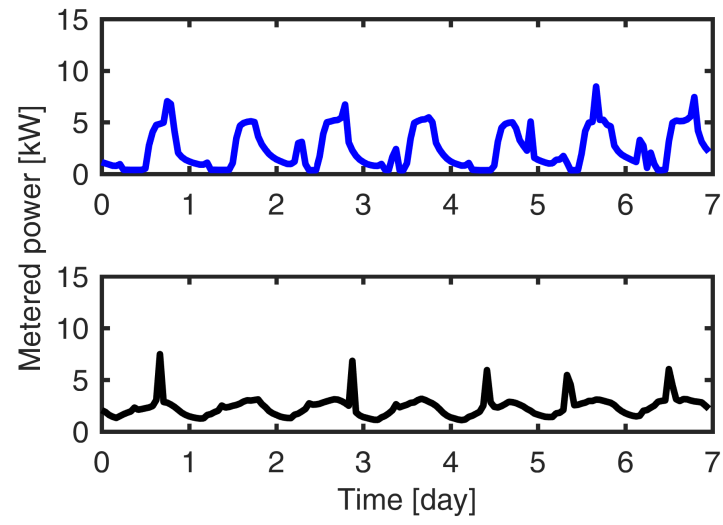

Figure 3. Results from two building simulation tools on the daily and weekly load for a typical 3-bedroom, 1.5 bathroom house calculated during a summer week in California with CBECC-Res 2019 (top) and EnergyPlus(bottom).

for the house in the chosen summer week is very low. The building simulation tools can be used to generate instantaneous energy usage data over the day. Daily house load profiles of the reference and simulated data in CA for the summer week and KY for the winter week have satisfactory agreement (Figs. 3 and 4). It may be noted that variations from the measured instantaneous energy usage are introduced because of consumer behavior. The energy usage from the CBECC-Res 2019 software has a) resolution of one hour, while the time step for EnergyPlus is set to five minutes. The peaks from EnergyPlus are averaged through a period of an hour, for the purpose of comparison with the output from CBECC-Res, for example at hour t:

$$
P_{\text {hour }}(t)=\frac{\sum_{n=1}^{n=12} P_{5 \min }(n) \cdot \Delta n}{60},
$$

where $\Delta n$ is the time step set to five minutes.

The measured house load data has the resolution of 15 minutes (Fig. 4). It may be noted that human behavior adds randomness to the house load, which accounts for the differences between the measured and simulated schedules. Human behavioral modeling and its effect on the load are beyond the scope of this work.

\section{SIZING AND SCHEDUling FOR PV HYBRID ENERGY STORAGE SYSTEM}

The solar PV system capacity required to achieve NZE operation was calculated from the simulated annual average
Table II

WEEKLY AND ANNUAL ENERGY USAGE FOR AN EXAMPLE KENTUCKY HOUSE $(\mathrm{KWH})$

\begin{tabular}{lccccc}
\hline \multirow{2}{*}{ Load type } & \multicolumn{2}{c}{ Winter } & \multicolumn{2}{c}{ Summer } & Annual \\
\cline { 2 - 5 } & Exp & EP & Exp & EP & EP \\
\hline HVAC & 214 & 225 & 64 & 66 & 2,603 \\
EWH & 42 & 40 & 8 & 9 & 1,829 \\
Other loads & 182 & 181 & 93 & 92 & 6,689 \\
Total usage & 439 & 446 & 164 & 168 & 11,121 \\
\hline
\end{tabular}

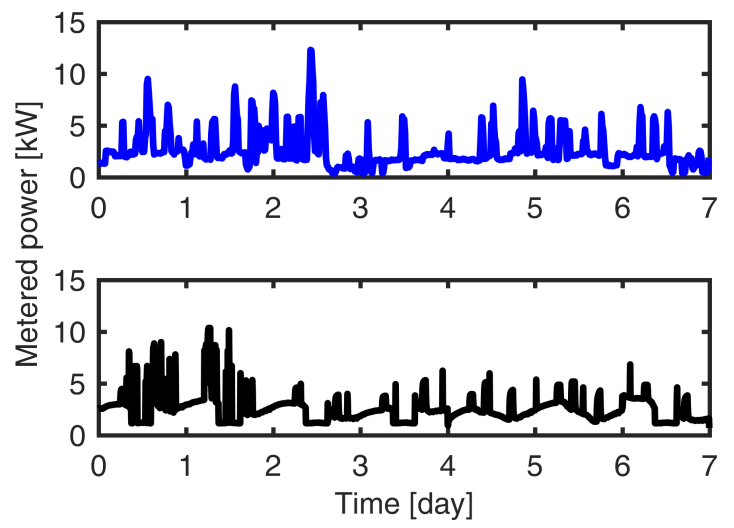

Figure 4. Experimental (top) and EnergyPlus simulation data for a house in southern KY in a winter week. The total weekly energy usage comply satisfactorily.

energy usage, based on

$$
\int P_{c}(t) d t \geqslant E_{H}
$$

where $P_{c}$ is the PV capacity; $E_{H}$, the total annual energy usage for the simulated house. The obtained PV system capacities to meet NZE targets for the chosen 3-bedroom 1.5bathroom residence in $\mathrm{CA}$, and the low-cost low-income house in southern $\mathrm{KY}$ are at least $7.2 \mathrm{~kW}$ and $6.5 \mathrm{~kW}$, respectively. It may be noted that a solar PV system with a capacity substantially exceeding the annual energy usage has a higher probability of meeting the NZE mandate but may lead to a high value of grid feed-in power during the middle of the day when loads are low, and a large power demand in the evening, when loads increase and PV energy reduces. This may potentially cause the "duck curve".

The EWH typically leads to repeating load peaks (Figs. 3 and 4). A residential battery can be sized and its operation scheduled to maximize the home owner's profitability by absorbing power from the grid during low price periods, and supplying the home loads when the electricity rate is high. This would benefit the home owner. In another approach, the battery can be sized and scheduled to minimize the peak-peak grid power flow variation, which would potentially benefit the utility company. As the focus in this paper is on mitigating the technical challenges brought forth by large NZE communities, the second sizing approach is discussed. The home electricity spending under a ToU tariff is calculated to evaluate the incentive for users to operate their energy storage systems to 


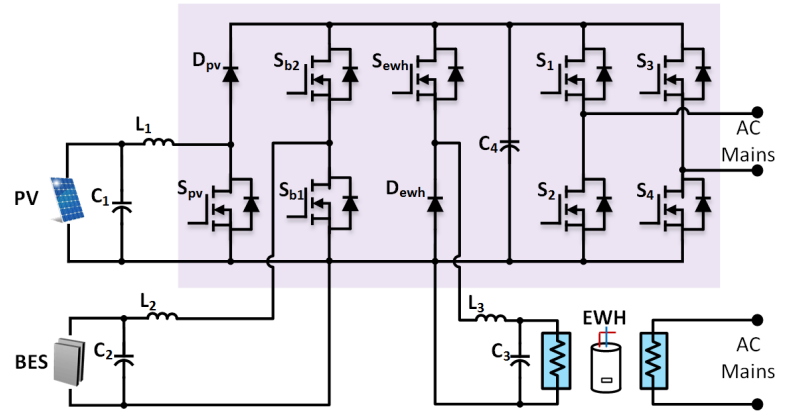

Figure 5. Example power electronic interface for an NZE house. The battery storage, electric water heater and PV array are interconnected with the DC bus via a multi-port converter.

minimize the grid power fluctuation.

A battery may be charged during midday to absorb the solar energy surplus, and be discharged later in the day to supply the EWH load, to avoid the absorption of peak power from the utility grid. In principle, a battery can be sized to mitigate the "duck curve" and reduce the residential peak load, however, its capacity and power rating would become prohibitively high. A hybrid PV energy storage system, including both battery and EWH controls is proposed. The EWH is a "unidirectional' energy storage, and it is expected that the solar PV generation coordinated controls of this system would reduce the residential peak load, and mitigate the "duck curve" issue with a reduced battery size. The energy stored in the EWH is

$$
\Delta Q=c m \Delta T=c m\left(T_{H}-T_{L}\right),
$$

where $Q$ is the energy; $c=4.18 \mathrm{~J} /(g \cdot k)$, the specific heat of water; $m$, the mass of water; $\Delta T$ the change of water temperature.

The provision of mixing valves allows the water to be maintained at a higher temperature, thereby increasing the thermal capacity of the tank. Control parameters for the EWH include the tank temperature. In this example, the highest and lowest temperatures of water in the tank are set to $70^{\circ} \mathrm{C}$ and $50^{\circ} \mathrm{C}$, respectively, ensuring the continued supply of hot water as the required temperature is always achievable by mixing cold water. The mass of water is fixed for a typical tank volume of 50 gallons, which will service 3-4 people. Given the volume of 50-gallons and deadband of $20^{\circ} \mathrm{C}$, the EWH can only absorb $4.4 \mathrm{kWh}$ thermal energy.

The control of EWH is realized, for example, by the proposed power electronic interface interconnecting the solar panels with the HyPVESS and the utility grid (Fig. 5). A multi-port converter inter solar PV panels, battery and variable power EWH to the DC bus, which feeds a single phase inverter connected to the utility and home loads. The converter is configured such that power flow to the PV and EWH systems is uni-directional. On the other hand, the power flow to the battery is bi-directional. In order to provide for high hot water draw, the EWH has both AC and DC elements, so that excess hot water demand can be serviced directly from the grid.

The switch $S_{p v}$ is modulated such that the PV operates at

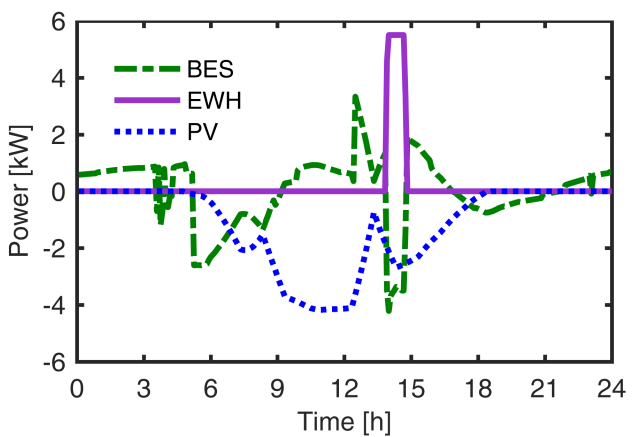

(a)

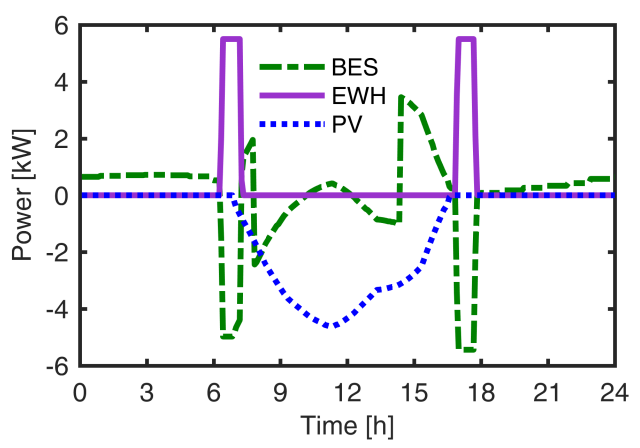

(b)

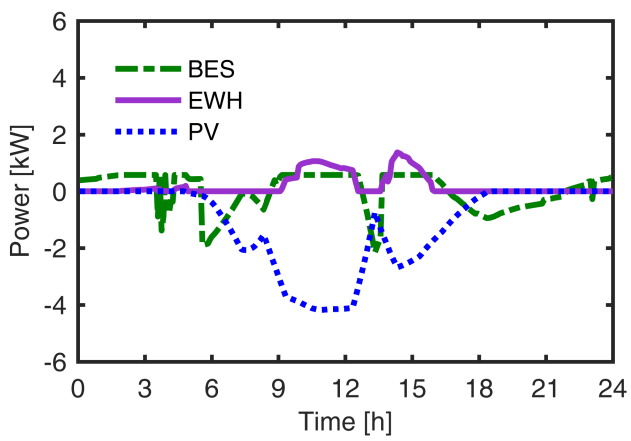

(c)

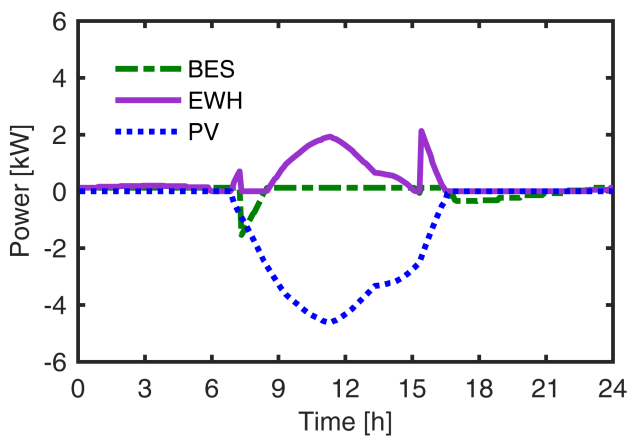

(d)

Figure 6. Battery and EWH schedules for the traditional case with a fixed power water heater for a representative (a) summer day and (b) winter day in California. Variable power water heater with controls co-ordinated with solar power availability for the same (c) summer day and (d) a winter day. 


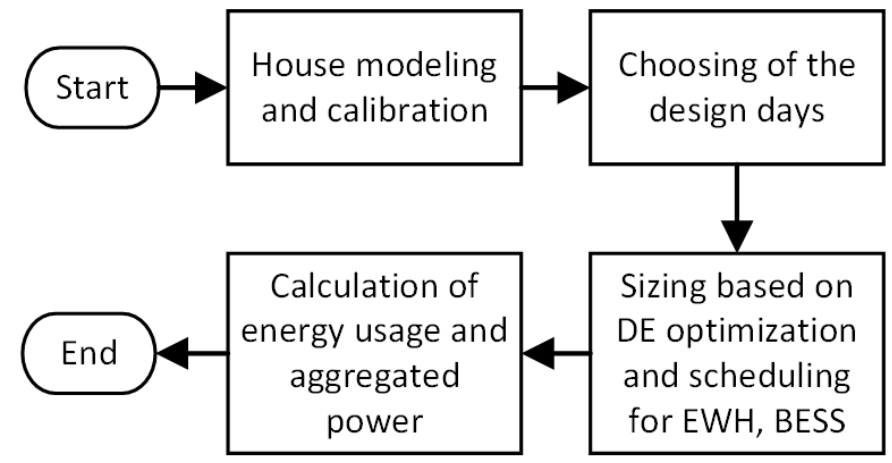

Figure 7. New figure-Procedure for the sizing of HyPVESS, calculation for electricity spending of NZE home and aggregated power of the distribution system.

its maximum power point. The inverter switches $S_{1}$ to $S_{4}$ are controlled to supply power to the grid and home loads at the specified voltage and frequency. The battery converter is controlled to regulate the dc bus voltage. Operation of $S_{b 1}$ and $S_{b 2}$ causes the battery to discharge and charge, respectively. The EWH absorbs the desired power from the DC bus by the modulation of $S_{\text {ewh }}$. The converter allows the DC bus voltage to be higher than that of the solar PV, battery and EWH.

In the traditional case, the EWH is generally equipped with conventional controls, which leads to a peak load that might not coincide with the peak of solar generation (Figs. 6 (a) and (b)). On the other hand, the solar PV coordinated controls of the EWH lead to the shifting of this load to a time in the middle of the day when solar power is in abundance (Figs. 6 (c) and (d)). This reduces the required energy capacity of the battery, which would otherwise have had to operate in the charging mode to absorb all the surplus solar power. Additionally, the use of a variable power EWH as opposed to a fixed power type reduces peak loads, which leads to a further reduction in the required energy and power ratings of the battery.

It may be noted that the energy consumed by the EWH depends on the hot water load, and is therefore the same in both fixed and variable power EWH types. Negligible heat loss, which is realized by good insulation, ensures the same EWH energy consumption irrespective of the times at which it operates, therefore, the operating schedule involves distributing a fixed energy.

The procedure for the systematic sizing of the HyPVESS is shown (Fig. 7). Following the modeling and calibration of the house energy consumption model, representative design days for summer and winter were chosen. Based on the PV generation and energy usage data for the design days, the differential evolution (DE) method was used for BES sizing and the scheduling for BESS and EWH. Electricity spending of individual NZE homes was calculated using the ToU and buy back rate based on $\mathrm{CA}$. The savings for individual homes were analyzed comparing the different electricity spendings caused by HyPVESS for the same house at the same day. The benefits of HyPVESS at distribution power system level were analyzed by comparing the peak power reduction.

The power balance for each home is expressed as

$$
\begin{aligned}
P_{M}(t) & =P_{P V}(t)+P_{B E S}(t) \cdot \eta+P_{R}(t), \\
P_{R}(t) & =P_{E W H}(t)+P_{R 1}(t),
\end{aligned}
$$

where, $P_{M}(t)$ is the metered power; $P_{P V}(t)$, the PV power generation; $P_{B E S}(t)$, the battery power; $\eta$, the battery efficiency (which, unless specified otherwise, is considered to be $100 \%$ considered for simplicity. A study of the real efficiency effects is later on included); $P_{R}(t)$, the residential load power; $P_{E W H}(t)$, the EWH load power; and $P_{R 1}(t)$, the residential load power excluding the EWH.

The ideal grid power flow would be constant throughout the day, however, such profiles are not practical due to solar power variability and peak loads. Therefore, each house is considered to deliver or absorb constant power to and from the grid for a certain time during the day in order to minimize the grid power fluctuation, and mitigate issues related to solar power variability Therefore, the power is fixed at two levels, as defined below,

$$
P_{M}(t)= \begin{cases}P_{1} & 0 \leq t \leq t_{1}, \\ P_{2} & t_{1} \leq t \leq t_{2} \\ P_{1} & t_{2} \leq t \leq 24 .\end{cases}
$$

With two such power levels considered, only 4-parameters are required to define $P_{M}(t)$, i.e. $P_{1}, P_{2}, t_{1}, t_{2}$. It may be noted that when this analysis is combined maximum profitability considerations, the metered power variation will change accordingly. The battery size and metered power would depend on the weather conditions. In this study, two representative summer and winter days are considered.

In the simulation, the battery is assumed to have the same amount of energy in the end as the beginning. Upon the integration of (4) over the whole day, taking the efficiency $\eta=1$ and setting $\int P_{B E S}(t) \cdot \eta d t=0$ yields

$$
\int P_{M}(t) d t=E_{P V}+E_{R}
$$

where, $E_{P V}$ and $E_{R}$ are energy generation by the solar PV system, and home energy usage over a day, respectively. Both these terms are fixed for given weather and residential load data, and thus, the term $\int P_{M}(t) d t$ can be calculated. This can be used to eliminate one of the 4-parameters composing the grid power definition using

$$
\int P_{M}(t) d t=P_{1} \cdot t_{1}+P_{2} \cdot\left(t_{2}-t_{1}\right)+P_{1} \cdot\left(24-t_{2}\right) .
$$

The variation in grid power flow is defined as

$$
\Delta P=\left|P_{1}-P_{2}\right| .
$$

A multi-objective optimization problem using $P_{1}, P_{2}$ and $t_{1}$ as variables is set up. The objectives considered are minimizing the battery energy capacity $\left(C_{B}\right)$, variation in grid output power $(\Delta P)$, and maximum battery power $\left(P_{B}\right)$, as follows,

$$
\operatorname{Min}\left(C_{B}, \Delta P, P_{B}\right)
$$


Table III

THE IMPACT OF BESS EFFICIENCY ON SYSTEM LOSS AND ELECTRICITY SPENDING

\begin{tabular}{|c|c|c|c|c|}
\hline BESS & \multicolumn{2}{|c|}{ Energy loss (kWh) } & \multicolumn{2}{|c|}{ Daily ES (\$) } \\
\hline $\begin{array}{c}\text { efficiency } \\
(\%)\end{array}$ & $\begin{array}{l}\text { summer } \\
\text { weekday }\end{array}$ & $\begin{array}{c}\text { winter } \\
\text { weekday }\end{array}$ & $\begin{array}{l}\text { summer } \\
\text { weekday }\end{array}$ & $\begin{array}{c}\text { winter } \\
\text { weekday }\end{array}$ \\
\hline 80 & 2.73 & 0.81 & 8.97 & 1.80 \\
\hline 85 & 2.05 & 0.61 & 8.95 & 1.80 \\
\hline 90 & 1.37 & 0.41 & 8.94 & 1.80 \\
\hline 95 & 0.68 & 0.20 & 8.92 & 1.80 \\
\hline 100 & 0.00 & 0.00 & 8.91 & 1.80 \\
\hline
\end{tabular}

Total daily energy usage, summer: $58.13 \mathrm{kWh}$; winter: $24.25 \mathrm{kWh}$

where (9) is subject to (4-7).

At each instant of time, for a specified value of $P_{M}$, and knowing the values of $P_{P V}$ and $P_{R 1}$, the term $P_{B E S}-P_{E W H}$ can be calculated using (4). The battery and water heater schedules are separated considering that the water heater is capable of only energy absorption, unlike the battery which can sink or source power. The EWH tank size and power rating are decided based on the requirements of typical single water heater homes. Furthermore, the EWH schedule is co-ordinated with the PV power generation such that as far as possible it operates when solar energy is in abundance.

Other objectives including the financial profitability for the house owner can be stated as follows,

$$
\operatorname{Min}\left(\sum_{i}^{t}\left(P_{M}^{t} \cdot r_{c}^{t}-P_{M}^{t} \cdot r_{b}^{t}\right)\right),
$$

where, $P_{M}^{t}$ is the discrete form of $P_{M}(t)$ from (4); $r_{c}^{t}$, the utility charge rate at time $\mathrm{t}$, and $r_{b}^{t}$, the utility buy back rate at time $\mathrm{t}$.

\section{CAse Studies}

The ratings of the battery and EWH systems for each day are determined from an optimization study, using typical meteorological year (TMY) weather data and design days, which are representative of typical winter and summer days. A more exhaustive sizing methodology may involve a consideration of different weather conditions for a specific location, and sorting of the similar days of a year. Several thousand candidate values of these optimization variables are considered, and the process is exemplified for home load and PV generation on a summer's and winter's day in California (Fig. 8). It is seen that a battery rated for $3.5 \mathrm{kWh} / 2.2 \mathrm{~kW}$ would achieve power delivery to the grid with a maximum fluctuation of $2.3 \mathrm{~kW}$ in summer, and a battery rated for $1.4 \mathrm{kWh} / 1.5 \mathrm{~kW}$ would have a fluctuation for output power of $2.4 \mathrm{~kW}$ in winter. A battery rated for larger capacity, i.e. $3.5 \mathrm{kWh} / 2.2 \mathrm{~kW}$ for the summer case in CA is chosen in order to handle the worst case. This battery rating is approximately a quarter of that marketed by commercial battery manufacturers [46].

The results of optimal sizing for southern Kentucky, where the EWH electricity consumption is fairly low (Table. II) on the representative summer day show that even in this case, the proposed HyPVESS reduces the battery size required. The required minimal BESS capacity $C_{B}$ is reduced from $5.8 \mathrm{kWh} / 6.3 \mathrm{~kW}$ of the PVBES to $4.1 \mathrm{kWh} / 1.3 \mathrm{~kW}$ through the use of the EWH with the proposed controls. The two cases are marked with a $i s$ and a $\diamond$, respectively (Fig. 9 (a)).

The detailed net power flow for the best cases of California on both summer and winter days are based on the optimization results (Fig. 8). In the absence of energy storage, peak load are serviced by the absorption of power from the utility grid (Figs. 10 (a) and (b)). The time-of-use (ToU) utility charge rates and the buy back rate, which is 3.8 cents $/ \mathrm{kWh}$ for the case studies are based on CA [47], [48]. The electricity spending (ES) were calculated for the power flows (Fig. 10). Assuming the BESS efficiency is $100 \%$, the daily electricity spending for the same summer weekday were $\$ 10.08$ and $\$ 8.91$, without and with HyPVESS scheduling, respectively (Fig. 10 (a) and (c)). The electricity spending for the same winter weekday were reduced from $\$ 3.46$ to $\$ 1.80$ with the HyPVESS scheduling (Fig. 10 (b) and (d)). This analysis shows that the operation scheduling of the HyPVESS to operate each home as a dispatchable generator is able to reduce the electricity spending to benefit the individual houses. This would serve as an incentive to home owners to operate the HyPVESS so that each house behaves like a dispatchable generator.

The effects of BESS efficiency on the proposed HyPVESS is studied (Table. III). In line with expectations, for both the studied summer and winter weekdays, energy losses decrease as BESS efficiency increases. It is observed that the daily electricity spending does not vary significantly with the changes in BESS efficiency. This is due to the fact that the proposed sizing method enables the minimum BESS energy capacity with fewer BESS operations.

On the other hand, in NZE residences equipped with the HyPVESS, the operating schedules can ensure that the home provides dispatchable power to the grid, or behaves like a controllable load for relatively long duration of time (Figs. 10 (c) and (d)). The variation of power flow to the grid is determined by the solar PV generation, as well as by the rating and operating schedule of the energy storage system, and more particularly that of the battery. The calculated battery ratings would minimize the power flow fluctuations on typical winter and summer days. Increased battery ratings may be required if the number of cloudy days per year are higher, which may be the case in Kentucky, though not in California.

In order to evaluate the effect of the proposed home energy storage scheduling on an aggregated level, the behavior of the NZE homes at the district level is modeled by interconnection with an IEEE-13 node test feeder system, which is described in [49]. Sixty NZE homes with residential load and PV generation profiles modified according to the number of occupants and local weather variations are connected to node 634 (Fig. 11).

Four types of homes, conventional i.e. without solar PV and BES; PVStd, including solar PV and conventional EWH but no batteries; PVBES, equipped with solar PV, conventional 


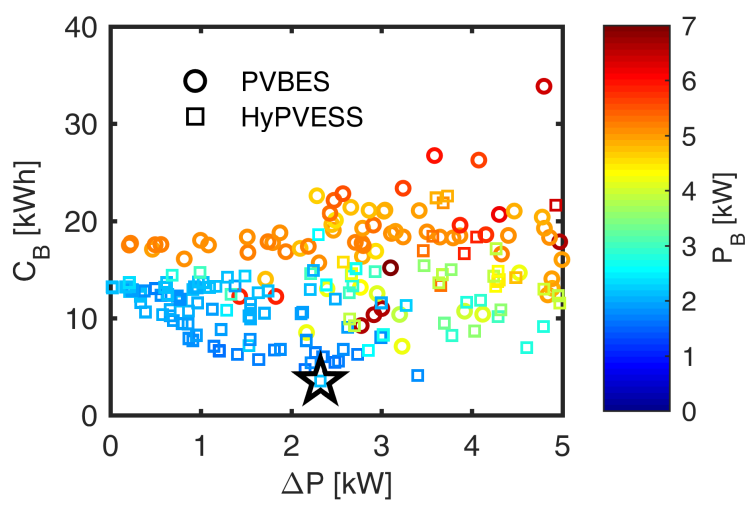

(a)

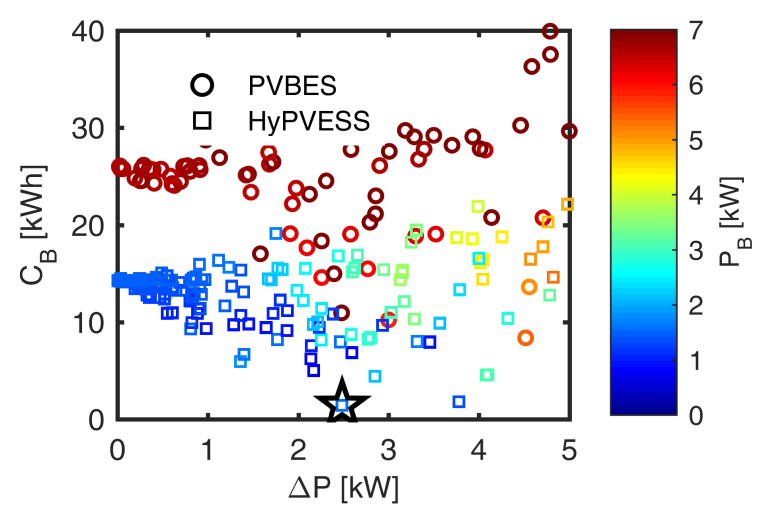

(b)

Figure 8. The variation of battery energy capacity, $C_{B}$ with grid power fluctuation, $\Delta P$ evaluated for several thousand values of $P_{1}, P_{2}$ and $t_{1}$ in NZE homes equipped with only BESS and PV (PVBES), and the hybrid PV energy storage system (HyPVESS) on a representative (a) summer's day and (b) winter's day for California.

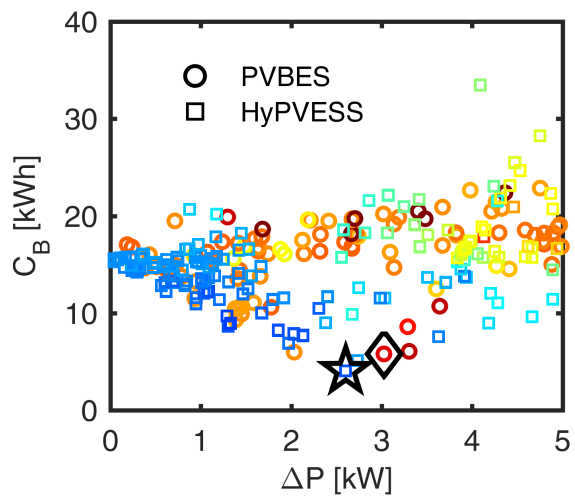

(a)

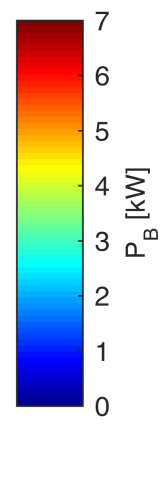

$4 \sum_{\underline{z}}$

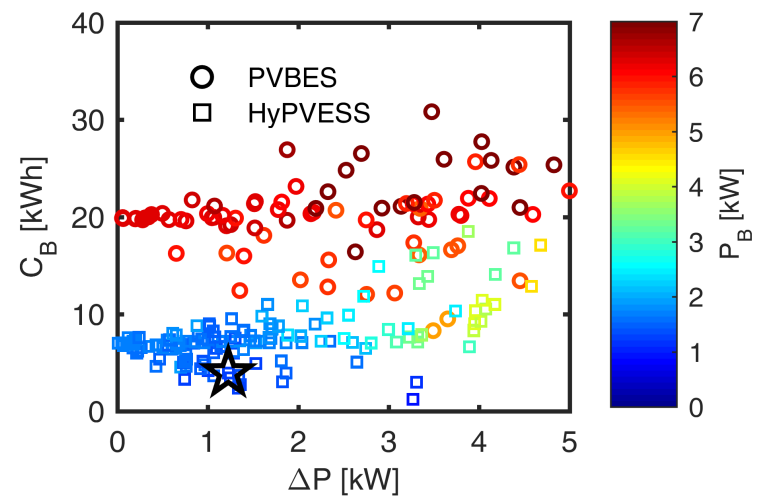

(b)

Figure 9. The DE results of battery sizing for southern Kentucky on a representative (a) summer's day and (b) winter's day. A battery rated for $4.1 \mathrm{kWh} / 1.3 \mathrm{~kW}$ is chosen based on the summer case and marked with a $2 \hat{3}$. The sized battery has a maximum output power fluctuation of $2.6 \mathrm{~kW}$ and $1.2 \mathrm{~kW}$ for the summer and winter days, respectively. Though better choices are available on the winter day, the limitation is set by the summer.

EWH, and batteries of the sized energy capacity; and the proposed HyPVESS containing both solar panels, batteries, and EWH with controls co-ordinated with solar PV generation are examined to verify the benefits of the proposed HyPVESS at the district level (Figs. 12 and 13). In case of the HyPVESS homes, the battery and EWH schedules and ratings are derived for each home as detailed in Section IV. The active power at the node 634 is monitored.

Homes of the PVStd type, which contain no storage can achieve NZE targets by feeding power to the utility during periods of plentiful solar power, and absorbing it when solar generation reduces. One of the limitations associated with this type of operation is that PV generation and load peaks are not coincident, leading to an excess inflow of power into the utility at and around midday. In contrast, during the evening, PV generation diminishes, and load rise, therefore excess power is absorbed from the utility grid at this time. This type of behavior leads to the "duck curve", which would be exacerbated for high PV penetration communities (Figs. 12 and 13). For large PV communities, a power system incorporating a number of fast responding gas plants would be required to service this rate of change of load, requiring tremendous investment. The peaks of power inflow and outflow could also potentially cause issues including overloading of distribution lines, transformers, and excessive voltage drop.

The PVBES homes, i.e. homes with batteries and conventional EWH systems can theoretically eliminate the "duck curve" and offset the peaks, however, the batteries required to achieve these objectives would have large energy capacities, and lead to high cost. In the HyPVESS case, i.e. homes with the variable power controllable EWH as well as batteries the "duck curve" is alleviated and peak demand is reduced, with a smaller size battery. When the homes are equipped with the HyPVESS, each one is controlled to deliver dispatchable power (Figs. 12 and 13). It is observed that peaks and the "duck curve" of the power flow to the grid are the minimum in all the cases for both summer and winter days (Figs. 12 and 13). Thus, these case studies demonstrate that the 


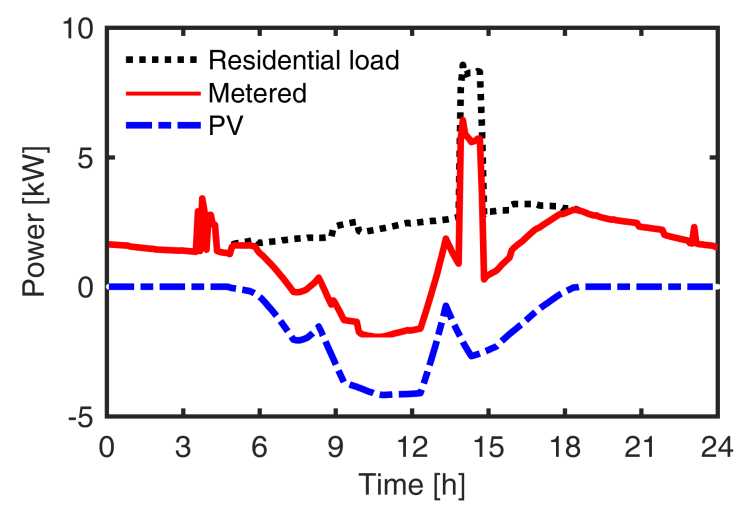

(a)

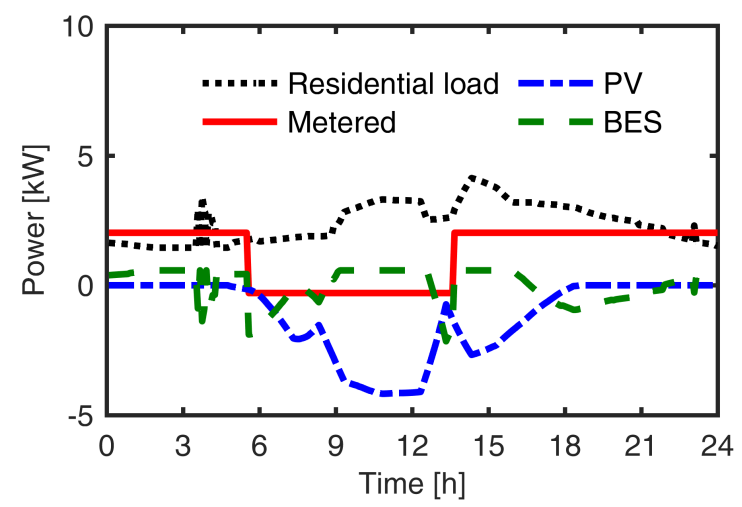

(c)

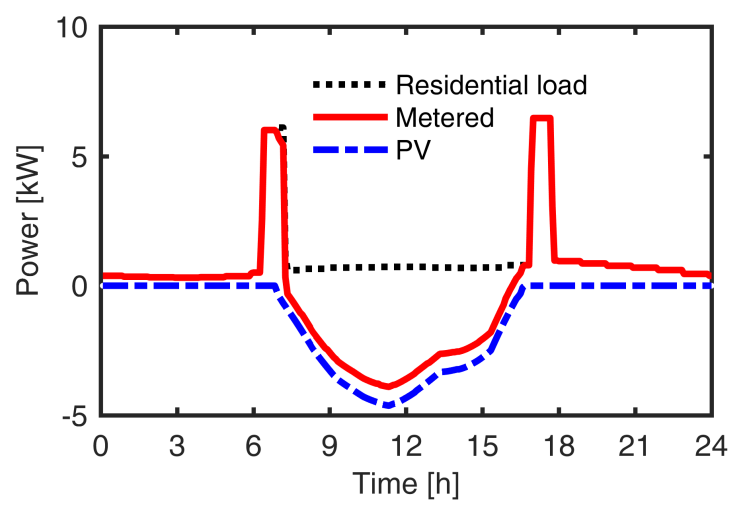

(b)

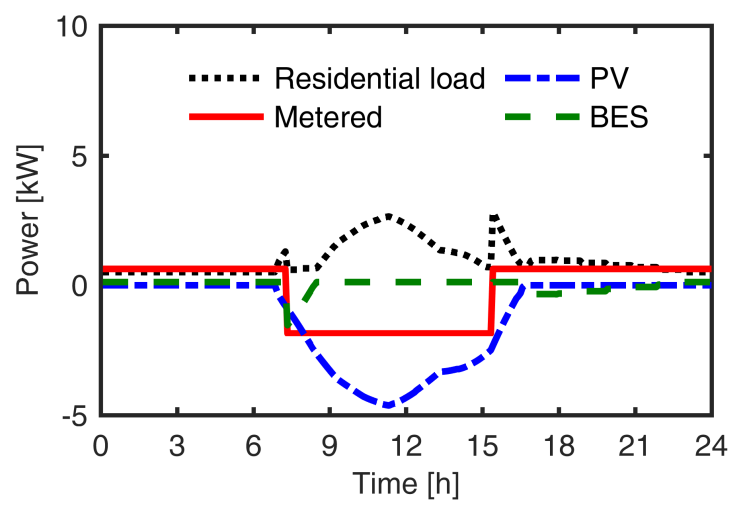

(d)

Figure 10. Power flow in a home equipped with a solar panel, but no storage, on (a) a summer's day, and (b) a winter's day. Power flow in a home with solar panels and coordinated control of energy storage systems on the same (c) summer's day and, (d) winter's day.

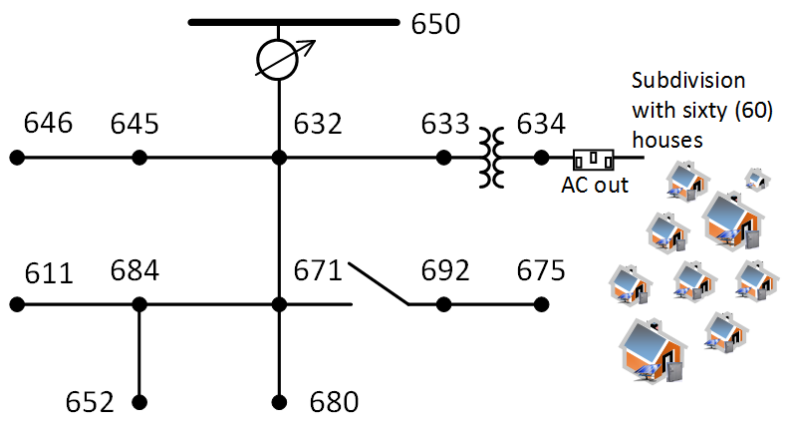

Figure 11. The IEEE 3-phase single line diagram 13-node feeder test case is adopted for the district level simulation. Sixty NZE houses are linked to node 634 .

proposed hybrid PV and battery energy storage system and controls can potentially mitigate the issues stemming from solar power variability, with a relatively small battery size. The proposed schedules for the battery and EWH can be combined with economic analysis and modified accordingly in order to maximize profitability for the consumer, in order to motivate more consumers to install home energy storage systems.

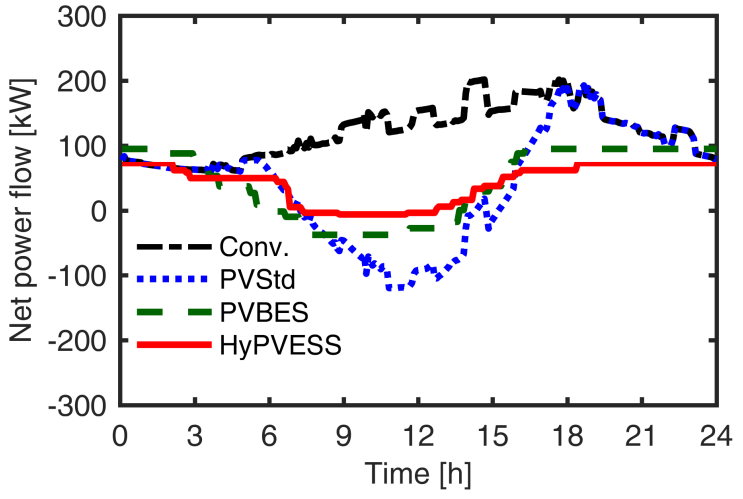

Figure 12. Power flow profile at node 634 of the IEEE 13-bus test system from Fig. 11 on a summer day.

\section{CONCLUSION}

This paper introduces a co-simulation framework called INSPIRE+D, which is capable of modeling the instantaneous energy usage and solar generation of a large community of buildings, and simulating their interconnection with the grid. A method to identify the minimum size of the solar PV panels in order to achieve net zero energy operation based 


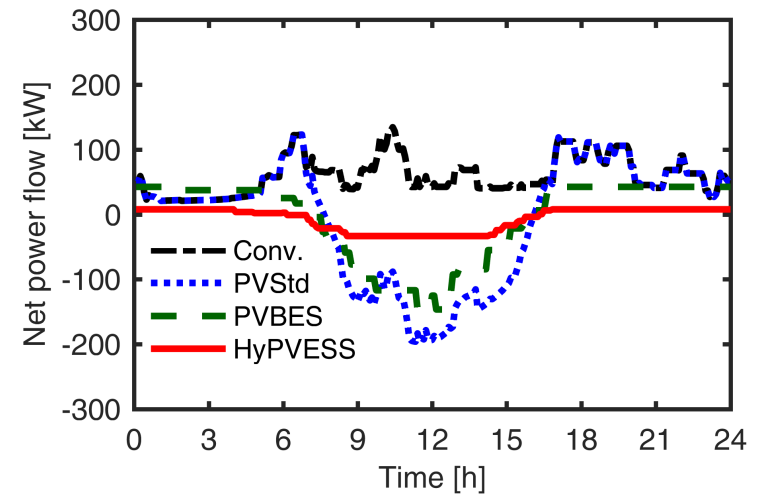

Figure 13. Power flow profile at node 634 of the IEEE 13-bus test system from Fig. 11 on a winter day.

on the simulated annual average energy usage is proposed. The energy usage models within the co-simulation framework are used to predict the electricity consumption for California and Kentucky, and validated based on the California Building Energy Code Compliance Residential Standards, and experimental data from southern Kentucky, respectively.

An energy storage system using batteries along with water heaters is proposed to alleviate the duck curve caused due to non coincident solar generation and load demands. This challenge is severe, in particular, for large communities of net zero energy houses, and additional flexibility requirements are imposed on the grid to service this variability. It was demonstrated through simulation studies on a large community of grid connected NZE homes that home energy storage systems can be controlled such that the grid power flow fluctuation can be minimized on typical winter and summer days, thereby mitigating technical challenges associated with solar power variability. For a case considering the ToU tariff and buy back rates from California, it is found that the electricity spending costs can be reduced significantly for representative summer and winter days through this control of the hybrid energy storage system. This offers an incentive for home owners to operate their energy storage systems in this manner. Simulation studies show that the same grid power flow can achieved with a $30 \%$ smaller battery through the use of the proposed controlled variable power water heaters.

A methodology based on multi-objective differential evolution for sizing and scheduling the operations of the hybrid energy storage system on typical winter and summer days is outlined. The objectives include the energy capacity and power ratings of the BESS, and the fluctuation of the net metered power. Economic objectives, such as to maximize consumer profitability can also be included. Furthermore, the sizing for BESS could be extended to consider charging/discharging patterns for different weather conditions over the year.

\section{ACKNOWLEDGMENT}

The support of University of Kentucky, the L. Stanley Pigman endowment, and of the SPARK program and the
Power and Energy Institute of Kentucky (PEIK) is gratefully acknowledged.

\section{REFERENCES}

[1] K. Peterson, P. Torcellini, R. Grant, C. Taylor, S. Punjabi, and R. Diamond, "A common definition for zero energy buildings," Prepared for the US Department of Energy by The National Institute of Building Sciences, US Department of Energy, 2015.

[2] Zero Net Energy, California Public Utilities Commission. [Online]. Available: http://www.cpuc.ca.gov/ZNE/

[3] Nearly zero-energy buildings - EU Commission. [Online]. Available: https://ec.europa.eu/energy/en/topics/energy-efficiency/buildings/ nearly-zero-energy-buildings

[4] S. Walker, T. Labeodan, W. Maassen, and W. Zeiler, "A review study of the current research on energy hub for energy positive neighborhoods," Energy Procedia, vol. 122, pp. 727-732, 2017.

[5] G. Mavromatidis, K. Orehounig, and J. Carmeliet, "Evaluation of photovoltaic integration potential in a village," Solar Energy, vol. 121, pp. 152-168, 2015.

[6] P. Denholm, M. O’Connell, G. Brinkman, and J. Jorgenson, “Overgeneration from solar energy in california. a field guide to the duck chart," National Renewable Energy Lab.(NREL), Golden, CO (United States), Tech. Rep., 2015.

[7] M. Zeraati, M. E. H. Golshan, and J. Guerrero, "Distributed control of battery energy storage systems for voltage regulation in distribution networks with high pv penetration," IEEE Transactions on Smart Grid, 2016.

[8] A. Sangwongwanich, Y. Yang, and F. Blaabjerg, "High-performance constant power generation in grid-connected pv systems," IEEE Transactions on Power Electronics, vol. 31, no. 3, pp. 1822-1825, 2016.

[9] R. Golden and B. Paulos, "Curtailment of renewable energy in california and beyond," The Electricity Journal, vol. 28, no. 6, pp. 36-50, 2015.

[10] S. Xiao, M. B. Shadmand, and R. S. Balog, "Model predictive control of multi-string pv systems with battery back-up in a community dc microgrid," in 2017 IEEE Applied Power Electronics Conference and Exposition (APEC). IEEE, 2017, pp. 1284-1290.

[11] S. Xiao and R. S. Balog, "An improved hierarchy and autonomous control for dc microgrid based on both model predictive and distributed droop control," in 2018 IEEE Applied Power Electronics Conference and Exposition (APEC). IEEE, 2018, pp. 3319-3325.

[12] X. Wang and F. Blaabjerg, "Harmonic stability in power electronic-based power systems: Concept, modeling, and analysis," IEEE Transactions on Smart Grid, vol. 10, no. 3, pp. 2858-2870, 2018.

[13] G. Sulligoi, A. Vicenzutti, V. Arcidiacono, and Y. Khersonsky, "Voltage stability in large marine-integrated electrical and electronic power systems," IEEE Transactions on industry applications, vol. 52, no. 4, pp. 3584-3594, 2016.

[14] G. Mokhtari, G. Nourbakhsh, and A. Gosh, "Optimal sizing of combined pv-energy storage for a grid-connected residential building," Advances in Energy Engineering, vol. 1, no. 3, pp. 53-65, 2013.

[15] X. Jin, J. Maguire, and D. Christensen, "Economic sizing of batteries for the smart home," 2018.

[16] T. Simpkins, K. Anderson, D. Cutler, and D. Olis, "Optimal sizing of a solar-plus-storage system for utility bill savings and resiliency benefits," in Innovative Smart Grid Technologies Conference (ISGT), 2016 IEEE Power \& Energy Society. IEEE, 2016, pp. 1-6.

[17] B. Zhang, Q. Yan, and M. Kezunovic, "Placement of ev charging stations integrated with pv generation and battery storage," in 2017 Twelfth International Conference on Ecological Vehicles and Renewable Energies (EVER). IEEE, 2017, pp. 1-7.

[18] Y. Sun, L. Gu, C. J. Wu, and G. Augenbroe, "Exploring hvac system sizing under uncertainty," Energy and Buildings, vol. 81, pp. 243-252, 2014.

[19] Z. Wu, S. Zhou, J. Li, and X.-P. Zhang, "Real-time scheduling of residential appliances via conditional risk-at-value," IEEE Transactions on Smart Grid, vol. 5, no. 3, pp. 1282-1291, 2014.

[20] K. Al-Jabery, Z. Xu, W. Yu, D. C. Wunsch, J. Xiong, and Y. Shi, "Demand-side management of domestic electric water heaters using approximate dynamic programming," IEEE Transactions on ComputerAided Design of Integrated Circuits and Systems, vol. 36, no. 5, pp. 775-788, 2016. 
[21] S. Shao, M. Pipattanasomporn, and S. Rahman, "Development of physical-based demand response-enabled residential load models," IEEE Transactions on power systems, vol. 28, no. 2, pp. 607-614, 2012.

[22] K. Kurohane, T. Senjyu, A. Yona, N. Urasaki, T. Goya, and T. Funabashi, "A hybrid smart ac/dc power system," IEEE Transactions on Smart Grid, vol. 1, no. 2, pp. 199-204, Sep. 2010.

[23] T. Alquthami and A. S. Meliopoulos, "Smart house management and control without customer inconvenience," IEEE Transactions on Smart Grid, vol. 9, no. 4, pp. 2553-2562, 2018.

[24] M. Shafie-Khah and P. Siano, "A stochastic home energy management system considering satisfaction cost and response fatigue," IEEE Transactions on Industrial Informatics, vol. 14, no. 2, pp. 629-638, 2018.

[25] S. A. U. Nambi, R. V. Prasad, and A. R. Lua, "Decentralized energy demand regulation in smart homes," IEEE Transactions on Green Communications and Networking, vol. 1, no. 3, pp. 372-380, 2017.

[26] H. T. Nguyen, D. T. Nguyen, and L. B. Le, "Energy management for households with solar assisted thermal load considering renewable energy and price uncertainty," IEEE Transactions on Smart Grid, vol. 6, no. 1, pp. 301-314, 2015.

[27] S. Althaher, P. Mancarella, and J. Mutale, "Automated demand response from home energy management system under dynamic pricing and power and comfort constraints," IEEE Transactions on Smart Grid, vol. 6 , no. 4 , pp. $1874-1883,2015$

[28] C. O. Adika and L. Wang, "Autonomous appliance scheduling for household energy management," IEEE transactions on smart grid, vol. 5, no. 2, pp. 673-682, 2014

[29] S. Zhou, Z. Wu, J. Li, and X.-p. Zhang, "Real-time energy control approach for smart home energy management system," Electric Power Components and Systems, vol. 42, no. 3-4, pp. 315-326, 2014.

[30] B. Moradzadeh and K. Tomsovic, "Two-stage residential energy management considering network operational constraints," IEEE Transactions on Smart Grid, vol. 4, no. 4, pp. 2339-2346, 2013.

[31] J. Dickert and P. Schegner, "A time series probabilistic synthetic load curve model for residential customers," in PowerTech, 2011 IEEE Trondheim. IEEE, 2011, pp. 1-6.

[32] Z. Zhao, W. C. Lee, Y. Shin, and K.-B. Song, "An optimal power scheduling method for demand response in home energy management system," IEEE Transactions on Smart Grid, vol. 4, no. 3, pp. 1391-1400, 2013.

[33] P. Radecki and B. Hencey, "Online model estimation for predictive thermal control of buildings," IEEE Transactions on Control Systems Technology, vol. 25, no. 4, pp. 1414-1422, 2017.

[34] D. Sturzenegger, D. Gyalistras, M. Morari, and R. S. Smith, "Model predictive climate control of a swiss office building: Implementation, results, and cost-benefit analysis," IEEE Transactions on Control Systems Technology, vol. 24, no. 1, pp. 1-12, 2016.

[41] J. Van Roy, B. Verbruggen, and J. Driesen, "Ideas for tomorrow: New tools for integrated building and district modeling," IEEE Power and Energy Magazine, vol. 11, no. 5, pp. 75-81, 2013.
[35] S. Vaghefi, M. Jafari, J. Zhu, J. Brouwer, and Y. Lu, "A hybrid physics-based and data driven approach to optimal control of building cooling/heating systems," IEEE Transactions on Automation Science and Engineering, vol. 13, no. 2, pp. 600-610, 2016.

[36] M. N. Sheha and K. M. Powell, "Dynamic real-time optimization of airconditioning systems in residential houses with a battery energy storage under different electricity pricing structures," in 13th International Symposium on Process Systems Engineering (PSE 2018), ser. Computer Aided Chemical Engineering, M. R. Eden, M. G. Ierapetritou, and G. P. Towler, Eds. Elsevier, 2018, vol. 44, pp. 2527 - 2532.

[37] D. Zhang, S. Li, M. Sun, and Z. O'Neill, “An optimal and learningbased demand response and home energy management system," IEEE Transactions on Smart Grid, vol. 7, no. 4, pp. 1790-1801, 2016

[38] S. Li, D. Zhang, A. B. Roget, and Z. O’Neill, "Integrating home energy simulation and dynamic electricity price for demand response study," IEEE Transactions on Smart Grid, vol. 5, no. 2, pp. 779-788, 2014.

[39] J. D. Rhodes, W. H. Gorman, C. R. Upshaw, and M. E. Webber, "Using beopt (energyplus) with energy audits and surveys to predict actual residential energy usage," Energy and Buildings, vol. 86, pp. 808-816, 2015.

[40] E. Wilson, C. Engebrecht-Metzger, S. Horowitz, and R. Hendron, "2014 building america house simulation protocols," National Renewable Energy Lab.(NREL), Golden, CO (United States), Tech. Rep., 2014.

[42] S. Duerr, C. Ababei, and D. M. Ionel, "Smartbuilds: An energy and power simulation framework for buildings and districts," IEEE Transactions on Industry Applications, vol. 53, no. 1, pp. 402-410, 2017.

[43] H. Gong, V. Rallabandi, D. M. Ionel, D. Colliver, S. Duerr, and C. Ababei, "Net zero energy houses with dispatchable solar pv power supported by electric water heater and battery energy storage," in 2018 IEEE Energy Conversion Congress and Exposition (ECCE). IEEE, 2018, pp. 2498-2503.

[44] J. H. Yoon, R. Baldick, and A. Novoselac, "Dynamic demand response controller based on real-time retail price for residential buildings," IEEE Transactions on Smart Grid, vol. 5, no. 1, pp. 121-129, 2014.

[45] H. Hao, C. D. Corbin, K. Kalsi, and R. G. Pratt, "Transactive control of commercial buildings for demand response," IEEE Transactions on Power Systems, vol. 32, no. 1, pp. 774-783, 2017.

[46] Tesla Powerwall. [Online]. Available: https://www.tesla.com/powerwall

[47] "Time-Of-Use (TOU) Rate Plans, Southern California Edison," https: //www.sce.com/residential/rates/Time-Of-Use-Residential-Rate-Plans, accessed: 2020-3-24.

[48] "Net Surplus Compensation Rate, Southern California Edison," https://www.sce.com/regulatory/tariff-books/rates-pricing-choices/ net-surplus-compensation, accessed: 2020-3-24.

[49] W. H. Kersting, "Radial distribution test feeders," in 2001 IEEE Power Engineering Society Winter Meeting. Conference Proceedings (Cat. No. 01CH37194), vol. 2. IEEE, 2001, pp. 908-912. 